\title{
SEARCHING FOR MATERIAL SYMMETRIES IN THE BURR WOOD OF THUJA BY A DIRECT CONTACT ULTRASONIC METHOD ON SPHERICAL SAMPLES
}

\author{
Mohammed El Mouridi ${ }^{1,2}$, Thierry Laurent ${ }^{1}$, Lö̈c Brancheriau ${ }^{3}$, Olivier Arnould ${ }^{1}$, \\ Abderrahim Famiri ${ }^{4}$, Abdelillah Hakam ${ }^{2}$, Joseph Gril ${ }^{1}$
}

\begin{abstract}
This work is part of a program that aims at studying the burr wood of thuja (Tetraclinis articulata). The goal of this work is to identify material symmetries of burr wood to improve its machining. To have a sufficient number of data and to limit the variability between samples, an ultrasonic experimental device, in direct contact on spherical samples, has been developed and improved. Until now, the geometry used in direct contact ultrasonic methods was either cubic or polyhedral allowing to obtain, on the same sample, 3 (cube) to 13 (polyhedron) measurements or usable data. By choosing a reasonable angular gap, the spherical geometry allows the ultrasonic velocity to be measured in 133 different directions on the same specimen. We present here the adaptation and development of the ultrasonic experimental device and results obtained on (i) aluminum chosen as a reference material, (ii) beech wood and (iii) burr wood of thuja.
\end{abstract}

Keywords: Material symmetry, ultrasonic method, direct contact, sphere, burr, wood, thuja, beech.

\section{INTRODUCTION}

Thuja (Tetraclinis articulate (Vahl.) Master) is a species endemic to the South-western coast of the Mediterranean sea and especially Maghreb, with the addition of some islands in the South-east of Spain and Malta island (Hatimi 1994). The largest area of thuja in North Africa is found in Morocco where it occupies approximately 608.000 ha (Hatimi 1994). Thuja has the particularity of issuing sprouts from their stump, which is rare among conifers (Hatimi 1994). Furthermore, it has the ability to develop burrs (Figure 1a and 1b), an excrescence found under the collar of the tree, into the earth. The burr wood of thuja, is composed of dark growths of high density, mixed in a "matrix" of woody tissue of density close to that of thuja (El Mouridi et al. 2011) (Figure 1c).

\footnotetext{
${ }^{1}$ Laboratoire de Mécanique et Génie Civil, Université Montpellier 2, CNRS UMR 5508, CC 048 Place Eugène Bataillon, 34095 Montpellier,

France. (mohamed.el-mouridi, thierry.laurent, olivier.arnould. joseph.gril)@univ-montp2.fr

${ }^{2}$ Équipe des Sciences et Technologie du Bois, Faculté des Sciences de Rabat, Université Mohammed V- Agdal : 4, Avenue Ibn Battouta B.P. 1014, Rabat, Maroc.ahakam@fsr.ac.ma

${ }^{3}$ CIRAD, Département PERSYST, 73 rue J.F. Breton, TA 10/16 34398, Montpellier Cedex 5, France. loic.brancheriau@ cirad.fr

${ }^{4}$ Centre de Recherche Forestière- BP 763 Agdal, Rabat, Maroc. afamiri2001@yahoo.fr

Corresponding Author : mohamed.el-mouridi@univ-montp2.fr

Received: 14.02.2011 Accepted: 19.07.2011
} 


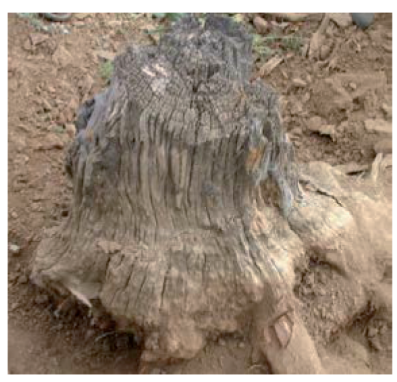

Figure 1a: Stump tree of thuja

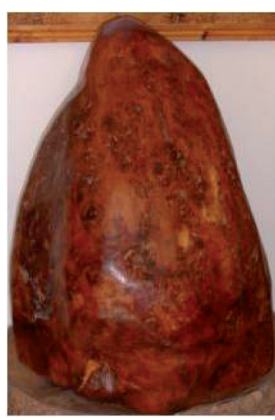

Figure 1b: Thuja burr

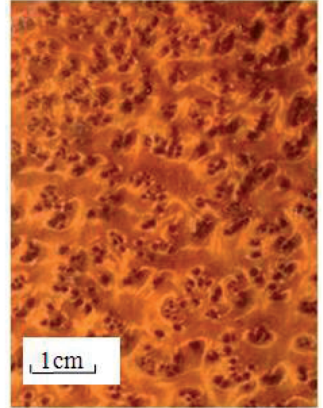

Figure 1c: Close view of thuja burr

Thuja burr plays an important economic and social role for the Moroccan artisanal sector. In Morocco, this sector employs about 1690 workers, 440 of them are master craftsmen and the handicrafts exports are on the order of 400.000 USD (Hatimi, 1994). When properly worked, the wood of thuja burr reveals a remarkable speckled pattern, leading to a real aesthetic value (Figure 1c). For this reason, this wood is very popular among marquetry artisans and cabinet makers. In recent decades, thuja burr has been the subject of a strong demand, the average quantity of thuja products consumption is about $212 \mathrm{~kg}$ of thuja burr/craftsman/month and 4 baulks/craftsman/month (Hatimi 1994). It results in a large deficit in the raw material supply (baulks and burr wood) sector and led to over-exploitation and degradation of thuja forests of Morocco.

Wood machining relies on material symmetries resulting from wood growth. As thuja burr does not exhibit natural symmetries such as those of wood, the improvement of its cutting process requires the identification of its symmetries. To reach this goal, we selected ultrasonic methods as they offer many advantages such as reliability, simplicity and rapidity of implementation (Bucur 2006). Moreover, these methods are pointed out for characterizing the material symmetries (or the mechanical behavior) and give information on the structural properties of a material (Bucur 2006).

There are two types of ultrasonic methods, the immersion method called goniometry and the direct contact method. For the first one, the transducers send waves to the specimen through a couplant liquid. This method is applied on parallelepipedic specimen (Préziosa 1982). For the direct contact method, as used in the present work, the transducers are directly stuck on parallel faces of the sample. According to Bucur (2006), it's the most rapid way to determine the material symmetry. It is generally applied on cubic specimens (Bucur 1985, Keunecke et al. 2007, Kolhauser et al. 2009) and polyhedral specimens with 16 or 26 faces (François et al. 1998). The use of this kind of geometry allows 3, 8 and 13, directions of measurements per specimen. However, the determination of material symmetries of a material by the ultrasonic method requires a large number of measurements (François et al. 1998) and a large number of specimens cut in different directions. The use of a single spherical specimen increases considerably the measurement direction number (133 in our case) and partly overcomes the problems of variability between specimens. Originally, the ultrasonic method by direct contact on spherical specimens is designed specifically for the determination of materiel symmetries. We use a theoretical modeling calculating the ultrasonic velocity from the material stiffness in any direction of a sphere (assuming density is constant in the specimen) to determine the $3 \mathrm{D}$ representation of the stiffness for isotropic and orthotropic materials. This method, applied to a quasi-orthotropic material like beech wood (Fagus sylvatica L.), allows the axes of orthotropy to be deduced from ultrasonic measurements.

Next, this method will be applied to the wood of thuja burr for determining its material symmetries. 


\section{MATERIAL AND METHODS}

\section{Material}

The thuja burr used in this study comes from the forest of Khemisset (Morocco). It was collected from a 50 -year thuja tree and has a dry density of $900 \mathrm{~kg} / \mathrm{m}^{3}$. The first sawing was carried out with a band saw to give $60 \mathrm{~mm}$ thick plates. These plates were then dried under cover until they reached $8 \%$ moisture content (E.M.C.). Bars, of square section $40 \mathrm{~mm}$ wide, were machined from these plates. Spherical specimens $36 \mathrm{~mm}$ in diameter were made in the bars using a numerical command lathe.

\section{Experimental set-up}

The experimental device (Figure 2) consists in a pulse generator 5800 PR-wideband $(35 \mathrm{MHz}$, Parametrics, Sofranel), an oscilloscope 54621A (60 MHz Agilent brand) and an "ultrasonic bench" consisting of a frame, an angle pinpointing tool and two longitudinal ultrasonic transducers Parametrics V303 SU (1 MHz, Ø $13 \mathrm{~mm})$.

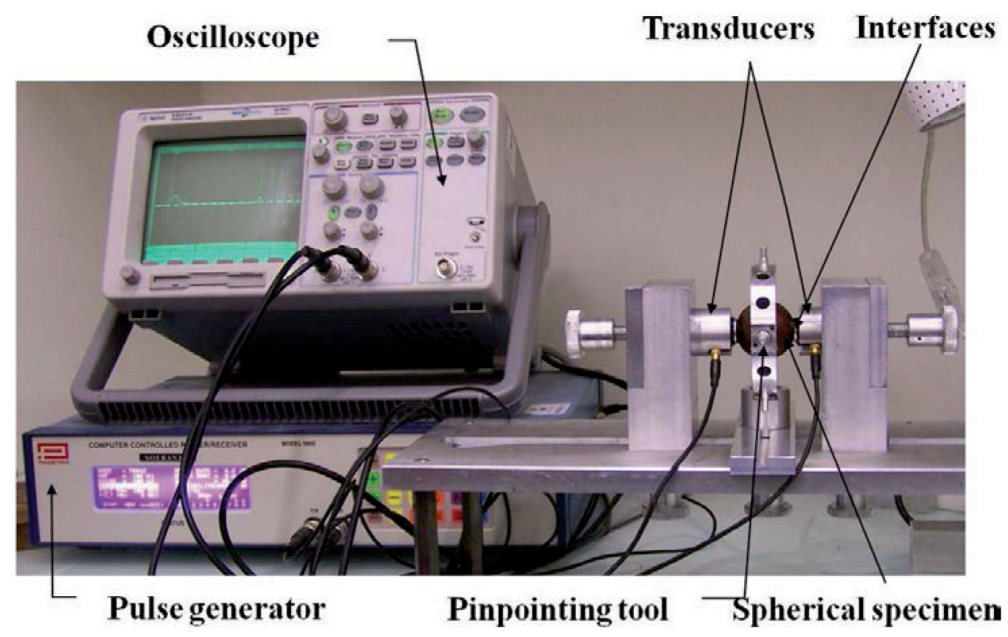

Figure 2. Experimental device

We conducted preliminary tests on spherical beech samples, directly in contact with the flat surface of the two transducers (point-like contact). These tests showed a poor transmission of ultrasonic waves. To solve this problem, we machined a (binding) interface in an aluminum alloy between the transducer surface and the sphere, to increase the contact area. This interface is centered on the extremity of the transducer and has a hemispherical contact area with the spherical material to be tested.

The presence of these two pieces induces a modification in the time of flight that must be corrected. The correction is done by measuring the difference in time of flight with and without interface, on a material that has a good transmission even with a point-like contact between the transducer and the sphere. Aluminum alloy fulfills this requirement.

The identification of the direction of wave propagation requires firstly to place the sphere properly. The solution chosen is to place the sphere into orthogonal axes marked by a needle. A positioning system (transversal and vertical adjustment) allows the center of the sphere to be placed on the transducers axis (Figure 3a). The tool requires an accurate marking of the sphere in the form of meridians and parallels (Figure $3 b$ ). The plotting of the meridians and parallels with an angular step of $15^{\circ}$ provides 133 directions of measurement. 


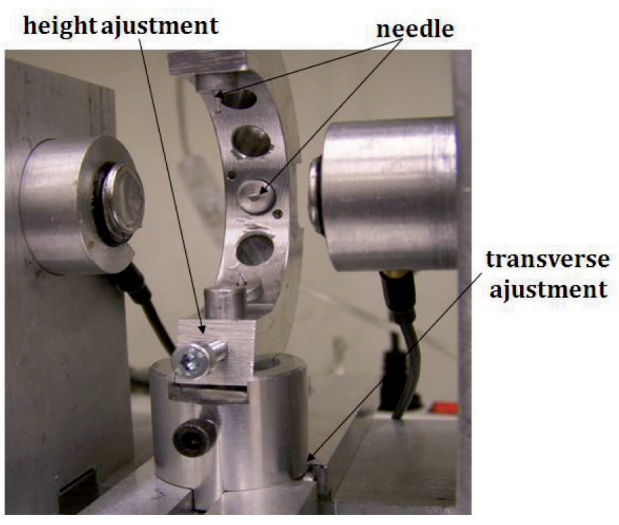

(a)

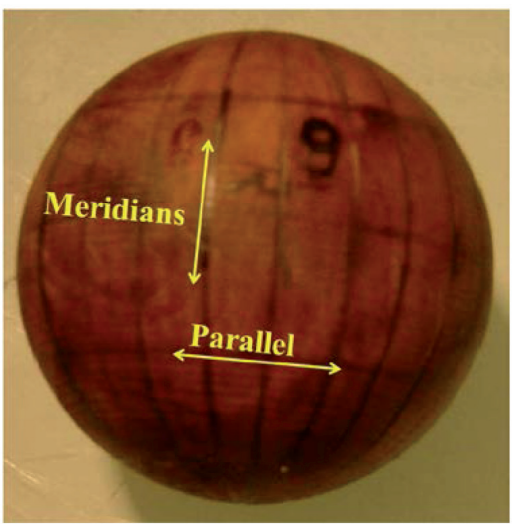

(b)

Figure 3. Experimental setup

a) Tool for direction pinpointing equipped with 2 perpendicular needles. b) Indexing mode

The ultrasonic tests are made according to an axis noted $\left(O, e_{2}^{*}\right)$ (Figure 4$)$. The wave propagation is supposed rectilinear and along a diameter path. $R\left(O, e_{1}, e_{2}, e_{3}\right)$ represents the selected reference frame for drawing parallels and meridians. The poles are in the $\mathrm{e}_{3}$ direction. $R\left(O, e^{*}{ }_{1}, e_{2}^{*}, e_{3}^{*}\right)$ is the reference frame relative to the propagation of ultrasonic wave. $R\left(O, e_{1}^{\prime}, e_{2}^{\prime}, e_{3}^{\prime}\right)$ is the intermediate reference frame. For locating all directions of measurement during tests, two angular parameters are needed, $\alpha$ : first rotation applied around $\left(O, e_{3}\right)$ and $\varphi$ : second rotation applied around $\left(O, e^{*}\right)$, which characterize the rotations between $R$ and $R^{*}$ (Figure 4).

The measured time of flight allows the velocity of the ultrasonic wave to be calculated along the axis $\left(O, e_{2}^{*}\right)$. This velocity is related to the rigidity along $e^{*}{ }_{2}$ by the expression:

$$
C(\alpha, \varphi)=\rho V^{2}=\frac{3 m}{\pi r \tau^{2}},
$$

where $\rho$ is the density of the specimen, $V$ the velocity of wave propagation along $\left(O, e^{*}{ }_{2}\right), \mathrm{m}$ the mass of the sphere, $r$ its radius and $\tau$ the time of flight along $\left(O, e_{2}^{*}\right)$.

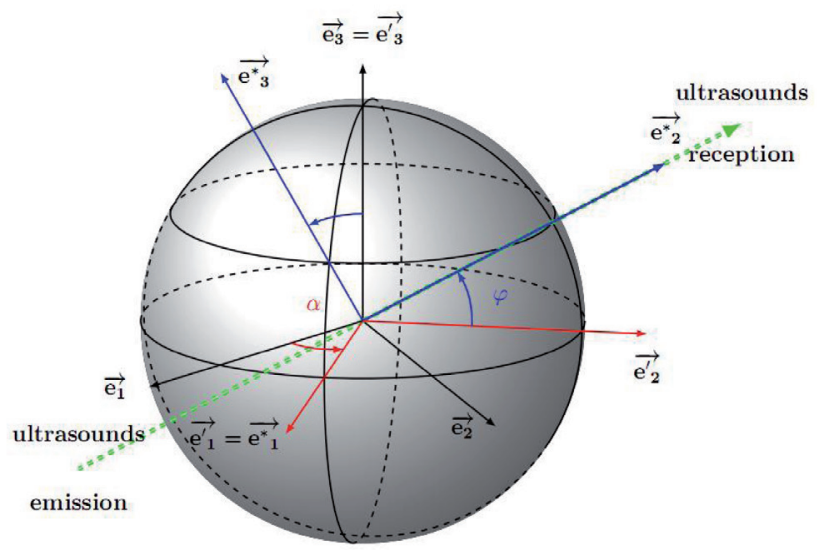

Figure 4. Geometric definition of an ultrasonic test 


\section{Theoretical modeling}

The aim of this theoretical modeling is to determine the stiffness of an anisotropic material in any direction according to:

- the coefficients $C_{i j}$ of the stiffness matrix (expressed in the principal axes),

- the measurement direction characterized by $\alpha$ and $\varphi$.

The stiffness tensor of an orthotropic material in its principal directions $\left(e_{1}, e_{2}, e_{3}\right)$ is written in Voigt notation (matrix representation):

$$
C_{i j}=\left(\begin{array}{cccccc}
C_{11} & C_{12} & C_{13} & 0 & 0 & 0 \\
C_{12} & C_{22} & C_{23} & 0 & 0 & 0 \\
C_{13} & C_{23} & C_{33} & 0 & 0 & 0 \\
0 & 0 & 0 & G_{23} & 0 & 0 \\
0 & 0 & 0 & 0 & G_{13} & 0 \\
0 & 0 & 0 & 0 & 0 & G_{12}
\end{array}\right)
$$

If the orientation of wood specimen deviates from the principal directions, the stiffness matrix must be transformed accordingly (Grimsel 1998). The required equation is obtained using a rotation of the stiffness matrix with an angle $\alpha$ around $\left(O, e_{3}\right)$ and an angle $\varphi$ around $\left(O, e_{1}^{*}\right)$ :

$$
C(\alpha, \varphi)=P_{R^{\prime} \rightarrow R^{*}}(\varphi) \cdot P_{R \rightarrow R^{\prime}}(\alpha) \cdot C \cdot P_{R^{\prime} \rightarrow R}(\alpha) \cdot P_{R^{*} \rightarrow R^{\prime}}(\varphi)
$$

where, for example, $P_{R^{\prime} \rightarrow R}(\alpha)$ is the matrix of rotation around $\left(O, e_{3}\right)$.

Then:

$$
\begin{aligned}
& C(\alpha, \varphi)=C_{11} \cos ^{4} \varphi \sin ^{4} \alpha+C_{22} \cos ^{4} \varphi \cos ^{4} \alpha+\sin ^{4} \varphi \\
& +2\left(C_{12}+2 G_{12}\right) \cos ^{4} \varphi \cos ^{2} \alpha \sin ^{2} \alpha \\
& +2\left(C_{13}+2 G_{13}\right) \cos ^{2} \varphi \sin ^{2} \varphi \sin ^{2} \alpha \\
& +2\left(C_{23}+2 G_{23}\right) \cos ^{2} \varphi \sin ^{2} \varphi \cos ^{2} \alpha .
\end{aligned}
$$

By varying $\alpha$ around the axis $\left(O, e_{3}\right)$ and $\varphi$ around the axis $\left(O, e^{*}{ }_{1}\right)$ we obtain the values of stiffness $\mathrm{C}(\alpha, \varphi)$ in all directions of the sphere. 


\section{RESULTS}

\section{Theoretical results}

We simulate an ultrasonic test on a sphere with an angular step of $10^{\circ}$ for $\alpha$ and $\varphi$. At first, we present the numerical results obtained for the isotropic aluminum alloy, then, those obtained for a wood sample. From the 3D representation of the stiffness $C(\alpha, \varphi)$ values in all directions in the sphere, we demonstrate the use of principal component analysis (PCA) to find the principal directions of wood.

\section{Aluminum Alloy}

The input parameters for the aluminum alloy are:

$$
E_{1}=E_{2}=E_{3}=69 \mathrm{GPa}, v_{12}=v_{13}=v_{23}=0.33, G_{23}=G_{13}=G_{12}=26 \mathrm{GPa}, \rho=2700 \mathrm{~kg} / \mathrm{m}^{3} \text {. }
$$
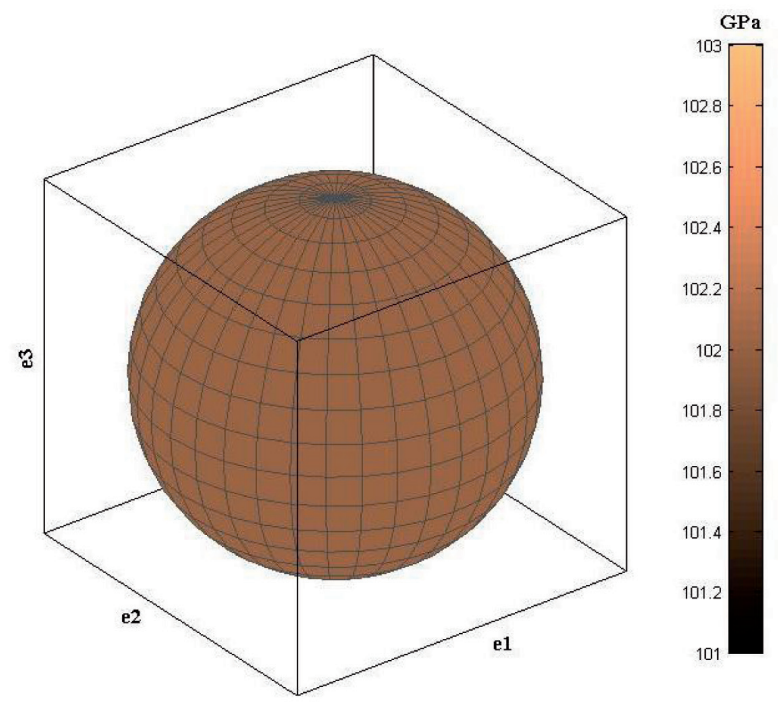

Figure 5. Values of $C(\alpha, \varphi)(\mathrm{GPa})$ as a function of the measurement directions for aluminum alloy.

The material is isotropic, the characteristic $C(\alpha, \varphi)$ is identical and equal to $102.2 \mathrm{GPa}$ whatever the direction of measurement considered. 


\section{Wood}

The axes $\left(e_{1}, e_{2}, e_{3}\right)$ correspond to axes $(R, T, L)$ of the material. The input parameters for the wood, are obtained from the empirical prediction of Guitard (1987), in the case of an air-dried hardwood (E.M.C $=12 \%$, density $\rho=650 \mathrm{~kg} / \mathrm{m}^{3}$ ): $\mathrm{E}_{1}=1.8 \mathrm{GPa}, E_{2}=1 \mathrm{GPa}, E_{3}=14.4 \mathrm{GPa}, v_{12}=0.68, v_{13}=0.39$, $v_{23}=0.03, G_{23}=0.9 \mathrm{GPa}, G_{13}=1.3 \mathrm{GPa}, G_{12}=0.4 \mathrm{GPa}$.

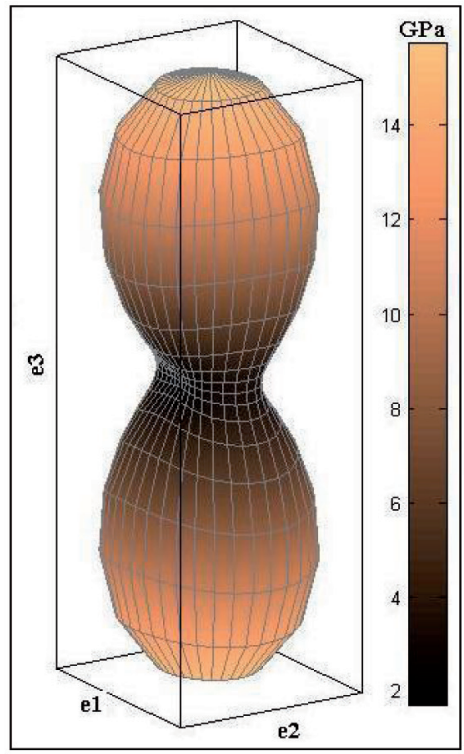

Figure 6. Values of $C(\alpha, \varphi)(\mathrm{GPa})$ as a function of the measurement directions for typical hardwood (E.M.C $=12 \%$, density $\rho=0.65 \mathrm{~g} / \mathrm{cm}^{3}$ ).

The associated stiffness vector $\left[C_{11}, C_{22}, C_{33}, C_{23}, C_{13}, C_{12}, G_{23}, G_{13}, G_{12}\right]$ is: $[2.6,1.5,15.5,1,1.1$, $1.5,1,1.3,0.4] \mathrm{GPa}$. The value of $C(\alpha, \varphi)$ varies according to the direction of propagation considered (Figure 6). When the measurement direction is that of the $\left(O, e_{3}\right)$ axis, $\left(O, e_{2}\right)$ axis and $\left(O, e_{1}\right)$ axis, the value is equal to $C_{33}, C_{22}$ and $C_{11}$ respectively.

\section{Experimental results}

\section{Application to beech wood}

We conducted a first application of the ultrasonic method by direct contact on beech wood (Fagus sylvatica L.), that gives an orthotropic and homogeneous sample at the sphere scale (annual rings shape close to a plane), for which we identified previously the axes of orthotropy through anatomical observation. We chose to misorient the sample by applying two successive controlled rotations, a first one $\theta=40^{\circ}$, and a second one $\psi=45^{\circ}$. The reference frame $R\left(O, e_{1}, e_{2}, e_{3}\right)$ is no more identical to that of orthotropy $(O, R, T, L)$. For an experiment done on a sphere of beech wood, the representation of experimental values of the stiffness (Figure 7) presents a shape similar to the theoretical one of figure 6, except for the rotation that needs to be determined. The principal component analysis (PCA), a general geometric method allowing to find the principal direction structuring the data, can be used for that purpose as the distributions of rigidities are symmetric and the geometric axes of rigidity correspond to the principal axes of the stiffness matrix. We apply the PCA method to the experimental stiffness values in two steps to find the axes of orthotropy, i.e, to find the values of the angles $\theta$ and $\psi$. First, the application of the PCA method from all values of $C(\alpha, \varphi)$ gives the direction of principal axis $\left(\mathrm{PA}_{1}\right)$ defined by the angle $\psi$ (Figure 7). We extract from the data the values belonging to the plane perpendicular to the principal axis $\left(\mathrm{PA}_{1}\right)$ and passing through the center $\mathrm{O}$; this plane contains the two other principal axes $\mathrm{PA}_{2}$ and $\mathrm{PA}_{3}$, both orthogonal to $\mathrm{PA}_{1}$. The shape of these values, in Figure 8 shows an elliptical distribution. To 
determine the major axis and minor axis of the ellipse, we perform a second application of the PCA method. The three directions of orthotropy are thus determined.

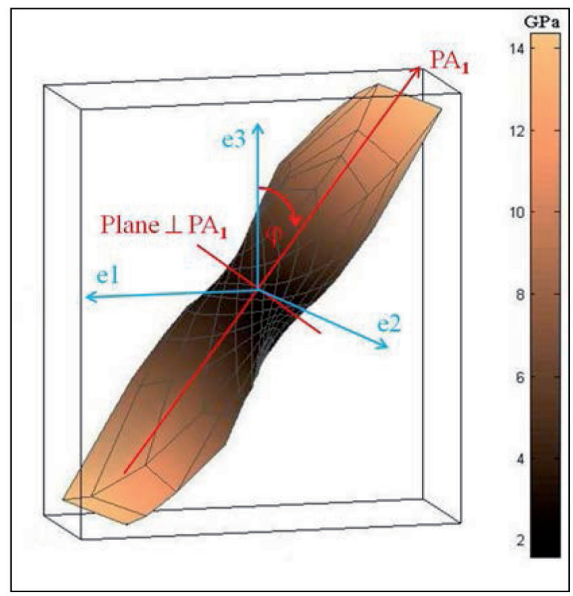

Figure 7. Values of $C(\alpha, \varphi)(\mathrm{GPa})$ as a function of the measurement directions in the reference frame $R\left(O, e_{1}, e_{2}, e_{3}\right)$ for beech wood.

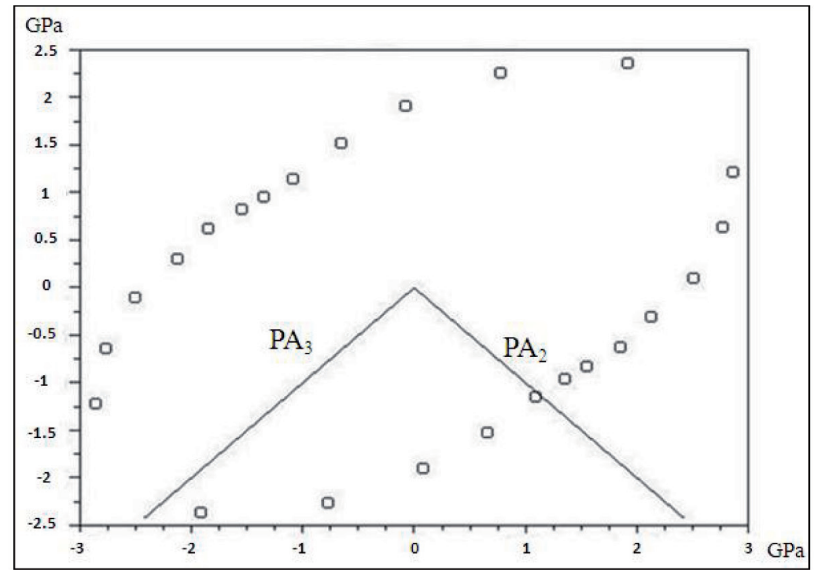

Figure 8. Experimental values of (GPa) of beech wood in the plane perpendicular to PA1 passing through $\mathrm{O}$.

We obtained the following results:

- $46.5^{\circ}$ for the $\psi$ angle, imposed experimentally at $45^{\circ}$;

- $33.4^{\circ}$ for the $\theta$ angle, imposed experimentally at $40^{\circ}$;

These results represent an error on the determination of directions $R, T$ and $L$ equal to $6.6^{\circ}, 4.8^{\circ}$ and $5^{\circ}$ respectively. The PCA method thus gives the three axes of orthotropy with a relatively good accuracy. The table 1 gives the values of stiffness constants of beech wood, measured and those predicted by the empirical model of Guitard (1987) in the 3 principal axes of material symmetry $(R, T, L)$ : 
Table 1. Comparison between the measured stiffness values (GPa) and the ones predicted by Guitard's model.

\begin{tabular}{|c|c|c|}
\hline Beech wood & Measured values & Predicted values \\
\hline $\mathrm{C}_{11}$ & 3.6 & 2.8 \\
\hline $\mathrm{C}_{22}$ & 1.6 & 1.8 \\
\hline $\mathrm{C}_{33}$ & 14.4 & 15 \\
\hline
\end{tabular}

Therefore, the ratios of stiffness values in the 3 main directions (i.e., similar to ratio of anisotropy) are given in table 2 .

Table 2. Comparison between the ratio of anisotropy for the measured stiffness values and the ones predicted by Guitard's model.

\begin{tabular}{|c|c|c|}
\hline Anisotropy ratio & Measured values & Predicted values \\
\hline $\mathrm{C}_{11} / \mathrm{C}_{22}$ & 2.3 & 2.4 \\
\hline $\mathrm{C}_{33} / \mathrm{C}_{11}$ & 4 & 5 \\
\hline $\mathrm{C}_{33} / \mathrm{C}_{22}$ & 9 & 12.9 \\
\hline
\end{tabular}

\section{Application to the burr wood of thuja}

We applied the ultrasonic method on four spherical samples of thuja burr extracted from the same bar. We present here the results obtained on one sample only. As we don't know the principal directions, even by the anatomical observations, the poles of the spherical samples are randomly chosen for the drawing of latitude and meridians. $\left(\mathrm{O}, e_{3}\right)$ corresponds to the axis passing through the poles. The stiffness values calculated in the reference frame $\left(O, e_{1}, e_{2}, e_{3}\right)$, from ultrasonic measurements are shown in figure 9 . The result of the computation for the first principal axis $\left(\mathrm{PA}_{1}\right)$ using the PCA on all the values of stiffness calculated gives a value for $\psi$ equal to $65.6^{\circ}$.

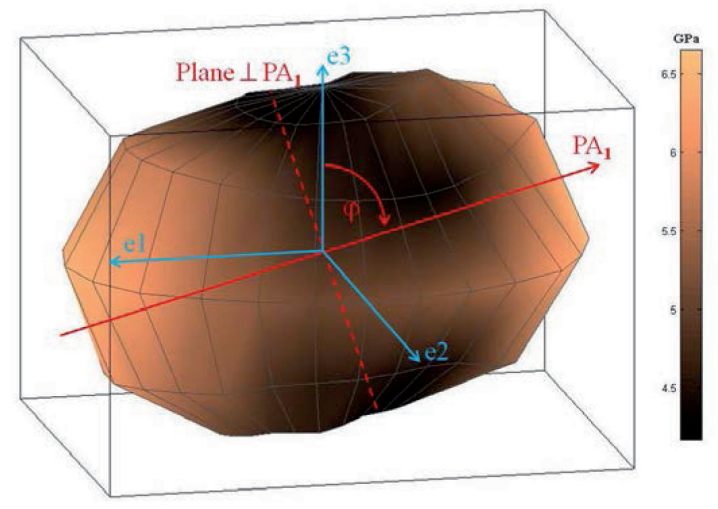

Figure 9. Values of $C(\alpha, \varphi)(\mathrm{GPa})$ as a function of the measurement directions in the reference frame $R\left(O, e_{1}, e_{2}, e_{3}\right)$ for burr wood of thuja. 
As for the beech, we then perform a reorientation by a rotation of $-\psi$, by recalculating the values of $C(\alpha, \varphi)$. From these new values we retain only those belonging to the direction perpendicular to $\mathrm{PA}_{1}$ axis passing through $\mathrm{O}$.

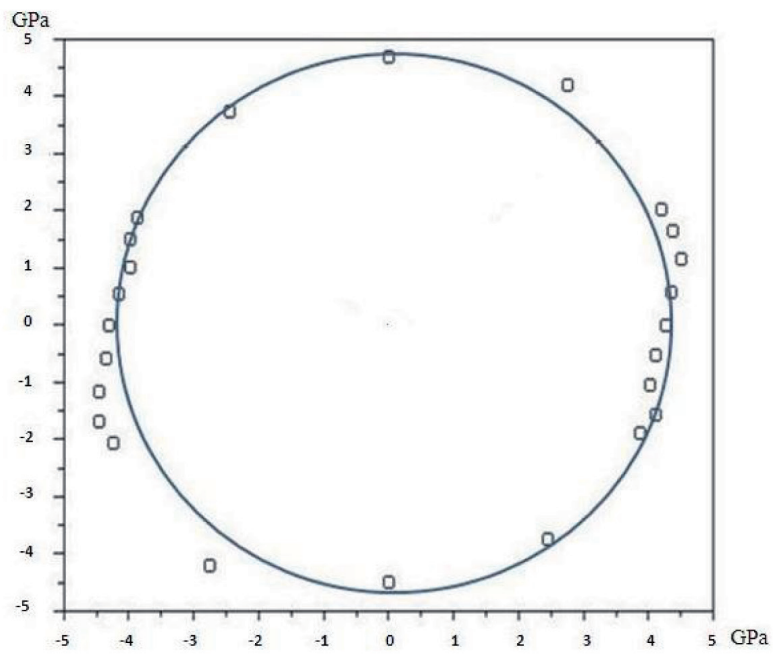

Figure 10. Experimental values of $C(\alpha, \varphi)(\mathrm{GPa})$ of the

burr wood of thuja in the plane perpendicular to the principal axis $\mathrm{PA}_{1}$ passing through $\mathrm{O}$.

Figure 10 shows an almost circular distribution of values of $C(\alpha, \varphi)$. Contrary to the beech wood sample, it is not useful here to apply the PCA method a second time for determining the other axes. Indeed, this circular distribution reflects a transversely isotropic behavior of the thuja burr.

The values of stiffness constants of burr wood in the 3 principal axes of material symmetry are: $C_{11}=4.5, C_{22}=4.5 \mathrm{GPa}$ and $C_{33}=6.6 \mathrm{GPa}$.

Therefore, the values of the stiffness ratio between these 3 directions are:

$$
\frac{C_{33}}{C_{11}}=\frac{C_{33}}{C_{22}}=1.4
$$

The stiffness values in the axes 1 and 2 have the same order of magnitude contrary to that in the axis 3 , which is slightly higher (i.e., slight transversely isotropic behaviour).

\section{Discussion}

The experimental results show that the beech wood has a "stiffness map" (Figure 7) whose shape is similar to the theoretical one (Figure 6). The PCA, used here to identify the principal direction, is a general geometric method yielding the principal direction structuring the data. The main limitation of this method (for the present study) is its sensitivity to point concentration due to a higher density of measurements at the poles. This problem could be solved by using the weighted PCA. The difference in the angles values may be due not only to this measurement points density variation but also to inaccuracy during parallels and meridians indexing and during identification of measurement directions. Repeatability tests should be conducted to assess all sources of errors even they remain quite small. The stiffness values of beech wood (anisotropy ratios) found by this method have the same magnitude as those found in the literature on similar sample (Guitard 1987, Grimsel 1999, François 2000, Thibaut et al. 2001, 
Bucur 2006). Considering the small differences observed in table 1 and 2 between the measured values and the ones predicted by the empirical model of Guitard, the fact that this empirical model only takes the density into account (but not the microfibrils angle for example) and the quite small error in the misorientation angles determination (Figures 7 and 8), we considered that the ultrasonic method applied to spherical sample of wood and the PCA analysis are validated (for this kind of wood, or density, at least) and should be easily applied to any kind of material as it has been successfully used on aluminium sample too. This method is then very useful for obtaining a fast assessment of the elastic anisotropy and principal directions of a given material using only one sample. That is very important in the case of wood studies (e.g., elastic properties radial and tangential gradients in a log), as variability from one sample to another can be high. Moreover, this method could allow us to obtain more information on the stiffness matrix than only the $C_{i i}$ values by using a reverse identification of the stiffness matrix using the stiffness map.

In the case of the thuja burr wood, for which no data is available to our best knowledge, our experimental results show that thuja burr wood has a transverse isotropic behavior. Indeed, the stiffness map shows the presence of a slightly stiffer direction. In the plane perpendicular to this direction, the wood has a very low anisotropy expressed by an anisotropy ratio practically equal to 1 .

In the case of a hardwood, with density usually ranging from 300 to $800 \mathrm{~kg} / \mathrm{m}^{3}$, the values of anisotropy ratio vary from 4 to 10,5 to 20 and 1.2 to 2.5 for $C_{L L} / C_{R R}, C_{L L} / C_{T T}$ and $C_{R R} / C_{T T}$, and respectively (Guitard 1987, Green et al. 1999). Fibers and tracheids are the reinforcing elements according to their axis, most fibers are oriented along the axis of the trunk, which gives a fibrous reinforcement in the longitudinal direction and therefore a higher stiffness value. The presence of rays in the radial direction and their absence in the tangential direction leads to an increase in the radial direction from the tangential direction, which gives low values of stiffness constants in the tangential direction. While in the case of thuja burr wood the value of this ratio is less than 2 , which is very low. This result shows that the thuja burr wood has a completely different mechanical behavior compared to wood. In order to determine the origin of this low value of anisotropy ratio and also the quasi-isotropy in the transverse plane to the stiffer axis, we did an anatomical study to see the effect of the presence of strong excrescences and of the irregular growth of this material. The fibres cells close to these excrescences have grown parallel to them whereas there are significant angular variations between cells (that can reach $90^{\circ}$ ) in the "matrix" surrounding excrescences. This cells disorder explains the quasi-isotropic behaviour of the burr wood of thuja (El Mouridi et al. 2011) and the fact that, in average, values obtained on burr wood are between the values measured in the transverse $R$ - and $T$-directions $\left(C_{R R} \approx 2.6 \mathrm{GPa}\right.$ and $\left.C_{T T} \approx 1.3 \mathrm{GPa}\right)$ and in the longitudinal L-direction ( $C_{L L} \approx 15 \mathrm{GPa}$ ) of thuja wood (Dakak, 2002).

\section{CONCLUSION}

In this article we have presented the adaptation of an experimental bench for stiffness measurement by ultrasonic contact on spherical samples. This method has been used to find the material symmetries of the burr wood of thuja, based on a series of ultrasonic measurements in transmission on a spherical specimen. The application to a beech wood specimen allowed us to check the ability of the procedure in finding the axes of orthotropy for this particular material. The error on direction $\mathrm{R}, \mathrm{T}, \mathrm{L}$ was $6.6^{\circ}, 4.8^{\circ}$ and $5^{\circ}$ respectively. The experimental results of this method applied to the thuja burr show the existence of axis of symmetry such that the burr wood of thuja has a transverse isotropic behavior. For future studies, an alternative method for the determination of material symmetries is under development. This method consists in expressing the theoretical relation between a stiffness tensor given in any coordinate system and the resulting stiffness map, and then performing a reverse identification of these parameters using a least square method. 


\section{ACKNOWLEDGMENTS}

This work has been supported by the French-Moroccan projects: P.R.A.D N ${ }^{\circ} 16878$ WC (EGIDE) "Technological characterization and exploitation of the wood of burr of thuja" and CNRS/CNRST $\mathrm{N}^{\circ} 22626 /$ STIC $03 / 09$ "Control of cutting parameters for the wood of burl of thuja for its rational use in marquetry and cabinetmaking".

\section{REFERENCES}

Bucur, V. 1985. Ultrasonic velocity, stiffness matrix and elastic constants of wood. Journal of the Catgut Acoustical Society 44: 23-28.

Bucur, V. 2006. Acoustics of wood, Springer series in wood sciences, Timell, T.E. and Wimm, R. (eds). $2^{\text {nd }}$ edition. ISBN 3540261230. 418p

Dakak, J. 2002. La qualité du bois de Thuya de Maghreb (Tetraclinis articulata) et ses conditions de développement sur ses principaux sites phytoécologiques de son bloc méridional au Maroc. PhD Thesis, École nationale du Génie Rural, des Eaux et des forêts, Nancy, France.

EL Mouridi, M.; Laurent, T.; Famiri, A.; Kabouchi, B.; Almeras, T.; Calchera, G.; El Abid, A.; Ziani, M.; Gril, J.; Hakam, A. 2011. Physical characterization of the root burl wood of thuja (Tetraclinis articulata (Vahl) Masters). Accepted for publication in Physical and Chemical News Journal.

François, M.; Geymonat, G.; Berthaud, Y. 1998. Determination of the system of an experimentally determined stiffness tensor: application to acoustic measurements. International Journal of Solids and Structures 35(31-32): 4091-4106.

François, M. 2000. Vers une mesure non destructive de la qualité des bois de lutherie. Revue des composites et des matériaux avancés 19(3): 261-279

Green, D.W.; Winandy, J.E.; Kretschmann, D.E. 1999. Mechanical Properties of Wood. In: Wood Handbook.Chapter 4, Forest Products Laboratory, Madison, WI: U.S. Department of Agriculture, USA. 2-3

Grimsel, M. 1998. Computer-Aided Identification of Mechanical wood Properties. In: Wood Structure and Properties'98. Kurjatko, S. and Kudela, J. (eds), Zvolen, Slovakia: 185-195

Grimsel, M. 1999. Mechanisches Verhalten von Holz: Struktur und Parameteridentikation eines anisotropen Werkstoes. PhD Thesis, Technische Universität Dresden, Germany.

Guitard, D. 1987. Mécanique du matériau bois et composites. Cépadues Editions, France. 118-127

Hatimi, M. 1994. Approvisionnement du secteur artisanal en souches et bois de thuya dans la province d'Essaouira (SW du Maroc). Master thesis, École Nationale Forestière d'Ingénieurs, Salé, Morocco.

Keunecke, D., Sonderegger, W., Pereteanu, K., Lüthi, T., Niemz, P. 2007. Determination of Young's and shear moduli of common yew and Norway spruce by means of ultrasonic waves. Wood Science and Technology 41: 309-327.

Kohlhauser, C.; Hellmich, C.; Vitale-Brovarone, C.; Boccaccini, A.R.; Rota, A.; Eberhardsteiner, J. 2009. Ultrasonic Characterisation of Porous Biomaterials Across Different Frequencies. Strain 45: 34-44.

Preziosa, C. 1982. Méthode de détermination des constants élastiques du matériau bois par utilisation des ultrasons. PhD Thesis, Université d'Orléans, France.

Thibaut, B. ; Gril, J. ; Fournier, M. 2001. Mechanics of wood and trees: some new highlights for an old story. Comptes Rendus de l'Académie des Sciences - Series IIB - Mechanics 329(9):701-716. 